\title{
Spatial and temporal variability of personal environmental exposure to radio frequency electromagnetic fields in children in Europe
}

\author{
Laura Ellen Birks ${ }^{\mathrm{a}, \mathrm{b}, \mathrm{c}}$, Benjamin Struchen ${ }^{\mathrm{d}, \mathrm{e}}$, Marloes Eeftens ${ }^{\mathrm{d}, \mathrm{e}}$, Luuk van Wel $^{\mathrm{f}}$, Anke Huss ${ }^{\mathrm{f}}$, \\ Peter Gajšek $^{g}$, Leeka Kheifets ${ }^{\mathrm{h}}$, Mara Gallastegi ${ }^{\mathrm{i}, \mathrm{j}}$, Albert Dalmau-Bueno ${ }^{\mathrm{a}, \mathrm{b}, \mathrm{c}}$, Marisa Estarlich ${ }^{\mathrm{c}, \mathrm{k}}$, \\ Mariana F. Fernandez ${ }^{c, 1}$, Inger Kristine Meder ${ }^{m}$, Amparo Ferrero ${ }^{c, k}$, Ana Jiménez-Zabala, ${ }^{i, n}$, \\ Maties Torrent ${ }^{\mathrm{c}, \mathrm{o}}$, Tanja G.M. Vrijkotte ${ }^{\mathrm{p}}$, Elisabeth Cardis, ${ }^{\mathrm{a}, \mathrm{b}, \mathrm{c}}$, Jørn Olsen ${ }^{\mathrm{q}}$, Blaž Valič ${ }^{\mathrm{g}}$, \\ Roel Vermeulen ${ }^{\mathrm{f}, \mathrm{r}, \mathrm{s}}$, Martine Vrijheid ${ }^{\mathrm{a}, \mathrm{b}, \mathrm{c}}$, Martin Röösli ${ }^{\mathrm{d}, \mathrm{e}}$, Mònica Guxens ${ }^{\mathrm{a}, \mathrm{b}, \mathrm{c}, \mathrm{t}, *}$ \\ a ISGlobal, Barcelona, Spain \\ b Pompeu Fabra University, Barcelona, Spain \\ ${ }^{\mathrm{c}}$ Spanish Consortium for Research on Epidemiology and Public Health (CIBERESP), Instituto de Salud Carlos III, Madrid, Spain \\ d Departement of Epidemiology and Public Health, Swiss Tropical and Public Health Institute, Basel 4051, Switzerland \\ e University of Basel, Basel, Switzerland \\ ${ }^{\mathrm{f}}$ Institute for Risk Assessment Sciences (IRAS), Utrecht University, Utrecht, The Netherlands \\ ${ }^{\mathrm{g}}$ Institute of Non-ionizing Radiation (INIS), Ljubljana 1000, Slovenia \\ h Department of Epidemiology, School of Public Health, University of California, Los Angeles, USA \\ ${ }^{\mathrm{i}}$ BIODONOSTIA Health Research Institute, Dr. Begiristain Pasealekua, San Sebastian, Spain \\ ${ }^{\mathbf{j}}$ University of the Basque Country (UPV/EHU), Preventative Medicine and Public Health Department, Faculty of Medicine, Leioa, Spain \\ ${ }^{\mathbf{k}}$ Epidemiology and Environmental Health Joint Research Unit, FISABIO-Universitat Jaume I-Universitat de València, 46020 València, Spain \\ ${ }^{1}$ University of Granada, Department of Radiology and Physical Medicine, Instituto de Investigación Biosanitaria ibs. GRANADA, Granada, Spain \\ ${ }^{m}$ Danish National Birth Cohort, Statens Serum Institut, Copenhagen, Denmark \\ ${ }^{n}$ Public Health Division of Gipuzkoa, Basque Government, San Sebastian, Spain \\ ${ }^{\circ}$ ib-salut, Area de Salut de Menorca, Menorca, Spain \\ ${ }^{\mathbf{P}}$ Department of Public Health - Amsterdam Public Health Research Institute, Academic Medical Centre, University of Amsterdam, Amsterdam, The Netherlands \\ ${ }^{\mathrm{q}}$ Danish Epidemiology Science Centre, Department of Public Health, Aarhus University, Aarhus, Denmark \\ ${ }^{\mathrm{r}}$ Julius Center for Health Sciences and Primary Care, University Medical Center Utrecht, The Netherlands \\ ${ }^{s}$ School of Public Health, Imperial College London, London, UK \\ ${ }^{\mathbf{t}}$ Department of Child and Adolescent Psychiatry/Psychology, Erasmus University Medical Centre-Sophia Children's Hospital, Rotterdam, The Netherlands
}

\section{A R T I C L E I N F O}

Handling Editor: Kalantzi Olga Ioanna Keywords:

Cell phones

Children's health

Electromagnetic fields

Radio waves

Smart phones

Wireless technology

\begin{abstract}
A B S T R A C T
Background: Exposure to radiofrequency electromagnetic fields (RF-EMF) has rapidly increased and little is known about exposure levels in children. This study describes personal RF-EMF environmental exposure levels from handheld devices and fixed site transmitters in European children, the determinants of this, and the day-today and year-to-year repeatability of these exposure levels.

Methods: Personal environmental RF-EMF exposure $\left(\mu \mathrm{W} / \mathrm{m}^{2}\right.$, power flux density) was measured in 529 children (ages 8-18 years) in Denmark, the Netherlands, Slovenia, Switzerland, and Spain using personal portable exposure meters for a period of up to three days between 2014 and 2016, and repeated in a subsample of 28 children one year later. The meters captured 16 frequency bands every $4 \mathrm{~s}$ and incorporated a GPS. Activity diaries and questionnaires were used to collect children's location, use of handheld devices, and presence of indoor RF-EMF sources. Six general frequency bands were defined: total, digital enhanced cordless telecommunications (DECT), television and radio antennas (broadcast), mobile phones (uplink), mobile phone base stations (downlink), and Wireless Fidelity (WiFi). We used adjusted mixed effects models with region random effects to estimate associations of handheld device use habits and indoor RF-EMF sources with personal RF-EMF exposure. Day-to-day and year-to-year repeatability of personal RF-EMF exposure were calculated through intraclass correlations (ICC).

Results: Median total personal RF-EMF exposure was $75.5 \mu \mathrm{W} / \mathrm{m}^{2}$. Downlink was the largest contributor to total exposure (median: $\left.27.2 \mu \mathrm{W} / \mathrm{m}^{2}\right)$ followed by broadcast $\left(9.9 \mu \mathrm{W} / \mathrm{m}^{2}\right)$. Exposure from uplink $\left(4.7 \mu \mathrm{W} / \mathrm{m}^{2}\right) \mathrm{was}$ lower. WiFi and DECT contributed very little to exposure levels. Exposure was higher during day $\left(94.2 \mu \mathrm{W} / \mathrm{m}^{2}\right)$
\end{abstract}

\footnotetext{
* Corresponding author at: ISGlobal-Campus Mar, Doctor Aiguader, 88, 08003 Barcelona, Spain.

E-mail address: monica.guxens@isglobal.org (M. Guxens).
} 
than night $\left(23.0 \mu \mathrm{W} / \mathrm{m}^{2}\right)$, and slightly higher during weekends than weekdays, although varying across regions. Median exposures were highest while children were outside $\left(157.0 \mu \mathrm{W} / \mathrm{m}^{2}\right)$ or traveling $\left(171.3 \mu \mathrm{W} / \mathrm{m}^{2}\right)$, and much lower at home $\left(33.0 \mu \mathrm{W} / \mathrm{m}^{2}\right)$ or in school $\left(35.1 \mu \mathrm{W} / \mathrm{m}^{2}\right)$. Children living in urban environments had higher exposure than children in rural environments. Older children and users of mobile phones had higher uplink exposure but not total exposure, compared to younger children and those that did not use mobile phones. Day-today repeatability was moderate to high for most of the general frequency bands (ICCs between 0.43 and 0.85 ), as well as for total, broadcast, and downlink for the year-to-year repeatability (ICCs between 0.49 and 0.80 ) in a small subsample.

Conclusion: The largest contributors to total personal environmental RF-EMF exposure were downlink and broadcast, and these exposures showed high repeatability. Urbanicity was the most important determinant of total exposure and mobile phone use was the most important determinant of uplink exposure. It is important to continue evaluating RF-EMF exposure in children as device use habits, exposure levels, and main contributing sources may change.

\section{Introduction}

Over the past thirty years, new mobile communication technologies such as mobile phones and their base stations, Wireless Fidelity (WiFi) access points, among others, have been developed and continue to rapidly evolve. These mobile technologies represent the main source of exposure to radio frequency electromagnetic fields (RF-EMF) in the general population (van Deventer et al., 2011). As these sources grow more numerous every day, researchers continue to evaluate the safety of human exposure to RF-EMF, encouraging caution and emphasizing the need for further research (Ahlbom et al., 2008; Sienkiewicz et al., 2005; Röösli and Hug, 2011; Swedish Radiation Safety Authority, 2017; Baan et al., 2011). Several European studies have attempted to characterize the quantity and variability of exposure to RF-EMF in the general population and found exposures to be consistently far below recommended limits (Thomas et al., 2008a; Frei et al., 2009; BergBeckhoff et al., 2009; Viel et al., 2009; Bolte and Eikelboom, 2012; Vermeeren et al., 2013; Gajšek et al., 2015). Nevertheless, the public and scientific communities remain concerned about exposure to RFEMF, particularly in children (Calvente et al., 2016; Calvente et al., 2015; Kheifets et al., 2005; Redmayne, 2016; Markov and Grigoriev, 2015). First of all, there is concern that children today are exposed to more RF-EMF than ever before and that this accumulated exposure over a lifetime could lead to adverse outcomes which have not yet been evaluated (Redmayne, 2016; Markov and Grigoriev, 2015; Rosenberg, 2013; Otto and von Mühlendahl, 2007). Secondly, there is concern that exposure to RF-EMF at a young age, while organs and the brain are rapidly developing, could lead to adverse health effects in childhood or later in life (Rice and Barone, 2000). Therefore studies characterizing RF-EMF exposure in children have been identified as high priority by the World Health Organization (van Deventer et al., 2011).

Some studies have attempted to characterize RF-EMF exposure in children from fixed site transmitters (such as mobile phone base stations or broadcast antennas) through geospatial modeling (Merzenich et al., 2008; Hauri et al., 2014; Huss et al., 2015; Schoeni et al., 2016; Guxens et al., 2016). Other studies have used exposure meters and questionnaire data to characterize children's exposure from handheld devices (such as mobile phone or tablet) and indoor sources (cordless phone base stations or WiFi) (Vermeeren et al., 2013; Thomas et al., 2009; Heinrich et al., 2011; Valič et al., 2015; Juhász et al., 2011; Roser et al., 2017). These studies have found that variations and quantity of exposure to RF-EMF can depend on many complex factors, and solely geospatial modeling or only extrapolating exposure from questionnaire data cannot accurately capture RF-EMF exposure (Röösli et al., 2010; Bolte, 2016). Personal exposure meters are considered one of the most accurate tools in assessing environmental personal exposure, allowing researchers to capture different sources of exposure, evaluate how this exposure varies over time, and validate exposure prediction models (Röösli et al., 2010; Bolte, 2016; Inyang et al., 2008; Frei et al., 2010). While methods for assessing personal RF-EMF exposure continue to evolve, so do communication technologies and children's habits for using them; therefore it is necessary to continue evaluating this exposure with the newest technologies through personal measurement studies to better understand this exposure today and in the future in children. With the ever-increasing use of mobile communication devices in the general population, and with the age of first use dropping every year, it is critical to closely evaluate RF-EMF exposure in children.

In this study, we examined levels and sources of personal environmental RF-EMF exposure, as well as its determinants, including individual characteristics, handheld device use, and presence of residential indoor RF-EMF sources, over a period of up to three days in $>500$ children spanning ages 8-18 in five European countries using personal exposure meters between 2014 and 2016. We also assessed the day-to-day repeatability of these measurements in the whole sample and year-to-year repeatability in a smaller subsample whose measurements were collected twice in the same children, one year apart.

\section{Methods}

\subsection{Study design and population}

As part of three European projects to identify, describe, and assess health effects of exposure to RF-EMF in children (Vermeulen, 2016; Guxens, 2016; Röösli, 2016; Gallastegi et al., 2016), personal environmental RF-EMF exposure measurements were collected over a period of up to three days for 567 children, ages 8-18 years old, in Denmark, the Netherlands, Slovenia, Switzerland, and five regions of Spain (Gipuzkoa, Granada, Menorca, Sabadell, and Valencia). For 30 children that participated in the first round of measurements in Sabadell, Spain, measurements were repeated one year later in the same children. A standardized protocol was followed in all regions (Röösli et al., 2010).

In Denmark, the Netherlands, and Spain, children were randomly recruited for participation during follow-up visits in the local population-based prospective birth cohort. These were: the Danish National Birth Cohort (DNBC) (Olsen et al., 2001), the Amsterdam Born Children and their Development Study (ABCD) (van Eijsden et al., 2011), and the Spanish Environment and Childhood Project (INMA) (Guxens et al., 2012), respectively. In Slovenia, participants were recruited by direct invitation or public announcements (via website or advertisements in local media). In Switzerland, a little more than half of the participants were recruited from the Swiss prospective cohort study, Health Effects Related to Mobile phonE use in adolescentS (HERMES) (Roser et al., 2017; Schoeni et al., 2015a; Schoeni et al., 2015b). The rest of Switzerland's participants were recruited randomly from 10 communities of the canton Zurich within the framework of the ZuMe exposure study (Röösli et al., 2016). Informed consent was obtained from all participants' parents or guardians, or the children themselves, in accordance with each center's institutional review board or ethics committee. 


\subsection{Personal environmental RF-EMF exposure measurements}

Personal environmental exposure measurements to RF-EMF in the 87.5 MHz-6 GHz range (the frequency range of greatest concern for mobile communication technology) were collected using personal portable exposure meters, or "exposimeters" (ExpoM-RF, Fields At Work, Zurich, Switzerland) (Fields at Work - Products [Internet], 2016) between August 2014 and February 2016, depending on the region. The exposimeters weighed approximately $320 \mathrm{~g}$; dimensions were $16 \times 8 \times 4 \mathrm{~cm}$. The exposimeters were calibrated in Switzerland in August 2014, then in February and August 2015. Exposimeters used in this study measured personal environmental exposure to 16 different frequency bands, corresponding to various sources of RF-EMF (Supplementary Table S1), with a measurement interval of four seconds. We defined six general frequency bands: total, digital enhanced cordless telecommunications (DECT), television and radio antennas (broadcast), mobile phones (uplink), mobile phone base stations (downlink), and WiFi (Supplementary Table S1). Total referred to all measured frequency bands except Mobile $3.5 \mathrm{GHz}$ and ISM $5.8 \mathrm{GHz} / \mathrm{U} / \mathrm{NII} 1 / 2 \mathrm{e}$ (both rarely used frequencies for mobile phones and WiFi, respectively) because of crosstalk concerns with other bands (where power emitted in one frequency band is measured and reported in another band (Roser et al., 2017)), as their inclusion would overestimate the total exposure. When the ExpoM was charging, the battery cable acted as an antenna, resulting in an overestimation of FM radio exposure. This was corrected by replacing these measurements with the median exposure values obtained under the same conditions, i.e. when the exposimeter was at home, but not charging. Crosstalk within the DECT frequency band was corrected using a self-developed algorithm (Eeftens, 2017). The correction algorithm identified crosstalk by searching for periods of increased correlations between Mobile $1800 \mathrm{MHz}$ downlink and DECT bands and between Mobile $2100 \mathrm{MHz}$ uplink and DECT bands. Depending on the direction of cross-talk (Mobile - > DECT or DECT-
$>$ Mobile) the affected band's recorded values were replaced with the median value of exposure in said band while no crosstalk was found and while the same activity category was entered.

During the measurement period, children were instructed to behave as they normally would. Children wore the exposimeter for up to three consecutive days (up to $72 \mathrm{~h}$ ), with the device placed in a padded belt bag. Children were instructed to wear the bag around the waist when possible during the day, while some older children carried the device in a backpack. When situated somewhere for long periods (e.g. at home or school) or at night, children were instructed to place the exposimeter on a flat non-metallic surface (e.g. on a table) close by. The exposimeters had a global positioning system (GPS), which provided data on the location of the participant at all times. Parents of participants or in some cases children themselves also completed an activity diary using a smartphone operating in flight-mode. The diary asked parents or children to indicate detailed microenvironment information including presence in home (indoors or outdoors), school (the classroom, cafeteria, or playground) transport (via train, metro, tram, bus, or car), outdoor activity (stationary, walking, on bike, or on scooter), or other (theater, restaurant, shopping, gym, home of friend, or other). Questionnaires regarding individual characteristics as well as handheld device use and presence of residential indoor RF-EMF sources during the measurement period were also collected at the end of the measurements (variables and categories are listed in Table 1).

\subsection{Statistical analysis}

Diaries with implausible chronologies (e.g. changing locations from home to school without documented travel) were identified using $\mathrm{R}$ Statistical Software (R Core Team, 2013), then manually cleaned and corrected using the GPS coordinates and visualization of paths and measurements corresponding to diary entries. Briefly, inconsistencies between the GPS and diary information were automatically flagged by

Table 1

Characteristics of children by region.

\begin{tabular}{llllllllllll} 
Overall & Denmark & The Netherlands & Slovenia & Switzerland & Spain \\
\hline$(n=529)$ & $(n=47)$ & $(n=56)$ & $(n=54)$ & $(n=98)$ & Gipuzkoa & Granada & Menorca & Sabadell & Valencia \\
\hline & & & & & & & & & & &
\end{tabular}

\begin{tabular}{|c|c|c|c|c|c|c|c|c|c|c|}
\hline \multicolumn{11}{|l|}{ Individual characteristics } \\
\hline Age (in years) & $12.5(3.1)$ & $15.4(1.3)$ & $12.0(0.4)$ & $12.7(2.6)$ & $14.3(1.2)$ & $7.8(0.2)$ & $14.0(0.5)$ & $17.5(0.1)$ & $9.3(0.6)$ & $10.7(0.4)$ \\
\hline Female (vs male) & 49 & 51 & 52 & 54 & 51 & 51 & $0^{\mathrm{a}}$ & 51 & 55 & 44 \\
\hline Urban (vs rural or suburban) & 49 & 28 & 71 & 78 & 25 & 0 & 47 & 55 & 99 & 2 \\
\hline $\begin{array}{l}\text { At least one parent with university } \\
\text { education }\end{array}$ & 55 & 94 & 81 & 87 & 49 & 58 & 22 & 23 & 46 & 23 \\
\hline \multicolumn{11}{|l|}{ (vs secondary or primary) } \\
\hline 5 or + people in home (vs $\leq 4$ ) & 23 & 28 & 30 & 57 & 28 & 14 & 13 & 17 & 12 & 7 \\
\hline \multicolumn{11}{|l|}{ Device use habits } \\
\hline DECT in home (vs no) & 72 & 26 & 76 & 69 & 91 & 72 & 81 & 65 & 79 & 63 \\
\hline WiFi in home (vs no) & 95 & 98 & 95 & 91 & 92 & 87 & 90 & 93 & 99 & 80 \\
\hline Use of mobile phone (vs no) & 74 & 96 & 95 & 70 & 95 & 23 & 80 & 94 & 46 & 79 \\
\hline Use of smartphone (vs no) & 71 & 96 & 91 & 56 & 94 & 14 & 77 & 94 & 44 & 77 \\
\hline $\begin{array}{l}\text { Mobile phone call frequency } \geq 2 \text { calls/day } \\
\quad(\mathrm{vs}<2 \text { ) }\end{array}$ & 16 & 40 & 13 & 50 & 10 & 2 & 3 & 30 & 1 & 9 \\
\hline $\begin{array}{l}\text { Mobile phone call duration }>5 \mathrm{~min} / \text { day } \\
\quad(\mathrm{vs} \leq 5)\end{array}$ & 9 & 9 & 5 & 28 & 12 & 0 & 3 & 13 & 1 & 5 \\
\hline $\begin{array}{l}\text { Internet on mobile phone }>30 \mathrm{~min} / \text { day } \\
\text { (vs } \leq 30 \text { ) }\end{array}$ & 37 & 72 & 43 & 26 & 64 & 0 & 63 & 62 & 0 & 19 \\
\hline SMS frequency $>5 /$ day $(v s \leq 5)$ & 10 & 32 & 5 & 28 & 12 & 0 & 10 & 4 & 0 & 2 \\
\hline App-based messaging $>10 /$ day (vs $\leq 10$ ) & 34 & 40 & 34 & 13 & 62 & 0 & 63 & 85 & 3 & 19 \\
\hline $\begin{array}{l}\text { Mobile phone turned on in bedroom at } \\
\text { night (vs off, flight mode, or outside } \\
\text { bedroom) }\end{array}$ & 30 & 66 & 16 & 43 & 40 & 0 & 30 & 76 & 0 & 14 \\
\hline Use of tablet (vs no) & 39 & 51 & 54 & 20 & 38 & 37 & 30 & 26 & 40 & 49 \\
\hline
\end{tabular}

Abbreviations: DECT, digital enhanced cordless telecommunications; SMS, short message service; WiFi, Wireless Fidelity.

Values are mean (standard deviation) for continuous variables and percentages for categorical values.

${ }^{\text {a }}$ In this sample, the Granada region was comprised of all males. 
detecting violations of several "logical" rules. For example, inconsistencies were flagged if no travel activity was reported between "home" and "work", or between "home" and "school"; if the participant reported being at home while the GPS showed a geographical distance of $>50 \mathrm{~m}$ away from the home; if a participant travelled on foot or by bicycle/moped at speeds exceeding $70 \mathrm{~km} / \mathrm{h}$. If necessary, flagged violations of the logical rules were manually corrected by a study assistant tracing the GPS path on a map, and merged with the exposure measurement information. A participant was excluded if the diary had no information on activity, location, and microenvironment $(n=21$ or $4 \%)$. All calculations were performed in power flux density unit $(\mu \mathrm{W} /$ $\mathrm{m}^{2}$ ). Statistical analyses were carried out using STATA version 14 (StataCorp, College Station, TX, USA).

The exposimeters reported values below or above the quantification limit (Supplementary Table S1) specified by the developer. We censored values above the upper boundary $(5 \mathrm{~V} / \mathrm{m}$ or $3 \mathrm{~V} / \mathrm{m})$ and we replaced values below half of the lower quantification limit with half of the quantification limit.

We used time weighted average (TWA) calculations to estimate RFEMF exposure in each general frequency band over the whole measurement period, by diurnal period, and by weekday and weekend day. This procedure was chosen in order to account for different durations of measurement periods and for interruptions in the measurements due to participants forgetting to charge the device or due to some device failures. We first created 8 time slots during daytime (every $2 \mathrm{~h}$ between 6:00 and 22:00) and 1 time slot for nighttime (22:01-05:59). For each participant, we averaged the exposure of each time slot. A time slot was considered incomplete and not taken into account if $<30 \%$ of the data was available for that time slot. The cutoff of $30 \%$ was chosen to approximately reflect at least one full day of measurements. Mean exposure of the whole measurement period was calculated as TWA of all completed time slots. Mean exposure during the day was calculated as TWA of the 8 daytime slots and mean exposure during the night was the average exposure of the single nighttime slot. Mean exposure by weekday and by weekend day was calculated as TWA of all time slots of the corresponding days (i.e. from Monday to Friday and from Saturday to Sunday, respectively). Participants were excluded if $<24 \mathrm{~h}$ were recorded, the nighttime slot was incomplete, or 2 daytime slots were incomplete ( $n=17$ or $3 \%$ of total sample). These participants were excluded because the short measurement period collected could possibly misrepresent the participant's personal environmental RF-EMF exposure. In addition, we used arithmetic mean values to estimate RFEMF exposure to each general frequency band in each microenvironment.

To describe RF-EMF exposure from general frequency bands over the whole measurement period by region, by diurnal period, by day of the week, by microenvironment, and by types of travel we calculated median exposures, as well as other summary statistics. Our main descriptive analysis focused on the median of the TWA exposure distributions as a measure of central tendency due the approximately lognormal distribution of exposure levels in each region. We calculated the average contribution (\%) of each general frequency band to the total exposure in each region and in the whole sample using median exposures. We also calculated the contribution (\%) of total exposure in each microenvironment to the total exposure over the whole measurement period.

Associations of individual characteristics and device use habits with log-transformed individual RF-EMF exposures to each general frequency band were estimated using mixed models with random region effects. Geometric mean ratios and $95 \%$ confidence intervals were calculated. Models between individual characteristics and log-transformed exposures were unadjusted as we wanted to explore differences between individual characteristics, inherently representing differences in behavior and device use. Models between device use habits and logtransformed exposures were adjusted for individual characteristics as we hypothesized they could be potential confounding variables on the studied associations. Models were calculated without interactions. See supplementary materials for detailed descriptions of models (Tables S2 and S3).

To assess day-to-day repeatability, we calculated intraclass correlations (ICC) of log-transformed RF-EMF exposure to each general frequency band and of total exposure by diurnal period between two consecutive $24 \mathrm{~h}$ period by weekdays and weekend days separately. To assess repeatability over a year, we calculated ICC of log-transformed RF-EMF exposure values to each general frequency band and of total exposure by diurnal period over two $24 \mathrm{~h}$ periods one year apart taking the same type of day (weekday or weekend day). We also compared device use habits of these participants between both years using student's $t$-test or chi-square test, where applicable.

We performed two sensitivity analyses: i) to discern if exposure measurements differed among children that carried the exposimeter in a handbag or backpack instead of on the body, we repeated the analysis of total exposure in each region but stratified by where the child carried the exposimeter; and ii) to explore the regional exposure contributions of two frequencies that were excluded from the main analysis due to crosstalk concerns (Mobile $3.5 \mathrm{GHz}$ and ISM $5.8 \mathrm{GHz}$ ), we compared the medians of TWA total exposure with and without these two frequency bands (separately by region).

\section{Results}

A total of 529 ( $n=93.3 \%$ of those recruited) child participants had valid measurements for the whole measurement period (between 24 and $72 \mathrm{~h}$ ). Children carried the exposimeter for an average of $62 \mathrm{~h}$ each (SD $16.3 \mathrm{~h}$ ). The youngest children were in Gipuzkoa (8 years old), with the oldest children in Menorca (18 years old) (Table 1). Children were living mostly in urban environments, except in Denmark, Switzerland, Gipuzkoa, and Valencia where most children lived in suburban or rural environments. While device use habits varied by region, we summarize these habits for the whole sample (for region specific use habits, please see Table 1). Three-quarters of children reported using a mobile phone at least once a week, though this and all other handheld device use habits varied by region. Most children reported few phone calls $(<2$ calls per day) or short call duration ( $\leq 5 \mathrm{~min}$ per call) in all regions. Participants were generally more likely to use internet on mobile phone than make calls, with overall $37 \%$ reporting internet use on mobile phone for $>30$ min a day. Only $10 \%$ of children overall reported SMS messaging $>5$ times a day. Children were more likely to send messages via messaging apps with overall $34 \%$ sending $>10$ messages a day.

Median total personal environmental RF-EMF exposure was $75.5 \mu \mathrm{W} / \mathrm{m}^{2}$ (Table 2, Supplementary Table S4). Children in Granada and Sabadell had the highest median total exposure, and children in Switzerland had the lowest. Exposure from downlink contributed most

\section{Table 2}

Median exposure of radiofrequency electromagnetic fields power density ( $\mu \mathrm{W}$ / $\mathrm{m}^{2}$ ) from different general frequency bands over whole measurement period by region $(n=529)$.

\begin{tabular}{llllllll}
\hline Region & $\mathrm{N}$ & Total & DECT & Broadcast & Uplink & Downlink & WiFi \\
\hline Denmark & 47 & 89.6 & 0.2 & 11.9 & 9.4 & 33.8 & 2.9 \\
Netherlands & 56 & 65.8 & 0.7 & 7.7 & 3.1 & 40.6 & 3.3 \\
Slovenia & 54 & 60.7 & 0.2 & 9.8 & 2.8 & 31.3 & 0.9 \\
Switzerland & 98 & 39.3 & 0.1 & 5.4 & 6.0 & 9.5 & 1.3 \\
Spain Gipuzkoa & 49 & 55.8 & 0.0 & 20.2 & 2.4 & 12.0 & 1.5 \\
$\quad$ Granada & 30 & 177.8 & 0.5 & 73.5 & 3.8 & 35.0 & 3.3 \\
$\quad$ Menorca & 53 & 93.5 & 0.0 & 0.7 & 3.4 & 20.4 & 1.4 \\
\multicolumn{1}{c}{ Sabadell } & 99 & 107.7 & 1.0 & 17.5 & 3.1 & 44.5 & 2.0 \\
$\quad$ Valencia & 43 & 80.5 & 0.1 & 12.5 & 5.9 & 28.4 & 1.4 \\
Overall & 529 & 75.5 & 0.2 & 9.9 & 4.7 & 27.2 & 1.8 \\
\hline
\end{tabular}

Abbreviations: DECT, digital enhanced cordless telecommunications; WiFi, Wireless Fidelity.

Mathematical note: the sum of medians does not equal the total median. 


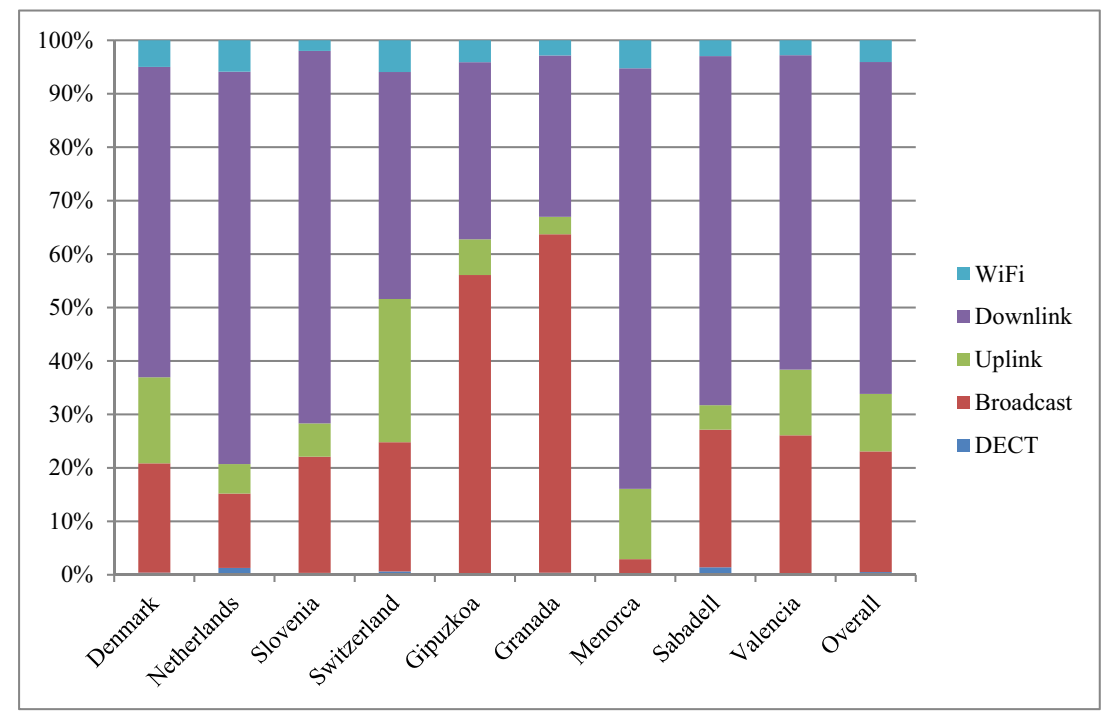

Fig. 1. Contributions (\%) of each general frequency band medians to total exposure medians over the whole measurement period by region and overall. Abbreviations: DECT, digital enhanced cordless telecommunications; WiFi, Wireless Fidelity.

to the total exposure (median of $27.2 \mu \mathrm{W} / \mathrm{m}^{2}$ ) followed by broadcast (median of $9.9 \mu \mathrm{W} / \mathrm{m}^{2}$ ) for most of the regions, except in Gipuzkoa and Granada where exposure was highest from broadcast, and in Switzerland where downlink, broadcast, and uplink contributed almost equally (Table 2, Fig. 1). Overall, exposure from uplink contributed to only a median of $4.7 \mu \mathrm{W} / \mathrm{m}^{2}$. WiFi and DECT contributed very little to exposure consistently across regions. Within exposure to general frequency bands, FM radio contributed most to broadcast, while Mobile $900 \mathrm{MHz}$ frequency contributed most to uplink and downlink (Supplementary Table S4). This was consistent across regions (data not shown).

In all regions, the median total exposure was higher during the day ( $94.2 \mu \mathrm{W} / \mathrm{m}^{2}$ versus $23.0 \mu \mathrm{W} / \mathrm{m}^{2}$ during night) (Table 3 ). The median total exposure was slightly higher during weekdays compared to weekends in Denmark, Slovenia, Switzerland, Granada, and Menorca, but slightly higher overall during weekends for the whole sample $\left(78.9 \mu \mathrm{W} / \mathrm{m}^{2}\right.$ during weekends versus $72.0 \mu \mathrm{W} / \mathrm{m}^{2}$ during weekdays). Median exposures were highest while children were outside $(157.0 \mu \mathrm{W} /$ $\mathrm{m}^{2}$ ) or traveling $\left(171.3 \mu \mathrm{W} / \mathrm{m}^{2}\right)$, and much lower at home $(33.0 \mu \mathrm{W} /$ $\left.\mathrm{m}^{2}\right)$ or in school $\left(35.1 \mu \mathrm{W} / \mathrm{m}^{2}\right)$. This was consistent across regions except in Granada where median total exposure was higher at home and in school $\left(125.5 \mu \mathrm{W} / \mathrm{m}^{2}\right.$ and $268 \mu \mathrm{W} / \mathrm{m}^{2}$, respectively). Total exposure at home contributed most to the total exposure over the measurement period (Supplementary Fig. S1). Within microenvironments, broadcast, uplink, and downlink exposures were higher while children were traveling (Supplementary Table S5).

Older children had higher uplink and WiFi exposures, but lower DECT and broadcast exposures (Table 4). Girls were more likely than boys to have higher uplink exposures. Children living in urban environments had higher total, DECT, and downlink exposures in comparison with children living in rural environments. Children whose parents had higher education were likely to have lower total and uplink exposures. Number of people living in home was not associated with exposure to any frequency band.

Handheld device use habits were not associated with total exposure (Table 5). Having a DECT phone in the home was associated with higher DECT and broadcast exposure. All handheld device use habits related to mobile phones (use of mobile phone, use of smartphone, any mobile phone call frequency and duration, any internet use on mobile phone, SMS frequency of 1-5 messages per day, any app-based messaging, and mobile phone turned on in the bedroom at night) were associated with higher uplink exposure. Use of a smartphone and intermediate levels of internet use on mobile phone (1-30 min/day) or app-based messaging (1-10 messages/day) were also associated with higher downlink exposure, while children that reported tablet use had lower downlink exposure. Highest levels of internet use on mobile phone ( $>30 \mathrm{~min} /$ day) or appbased messaging ( $>10$ messages/day) as well as having the phone turned

Table 3

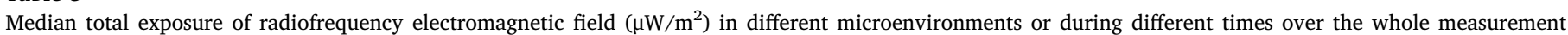
period, by region $(n=529)$.

\begin{tabular}{|c|c|c|c|c|c|c|c|c|c|c|c|c|c|c|c|}
\hline \multicolumn{2}{|l|}{ Region } & \multirow[t]{2}{*}{ Total } & \multicolumn{2}{|c|}{ Diurnal } & \multicolumn{2}{|c|}{ Days of week } & \multicolumn{4}{|c|}{ Microenvironment } & \multicolumn{5}{|l|}{ Types of travel } \\
\hline & & & Day & Night & Weekday & Weekend & Home & School & Outside & $\begin{array}{l}\text { While } \\
\text { traveling }\end{array}$ & Bus $(n=114)$ & $\operatorname{Car}(n=327)$ & $\begin{array}{l}\text { Train } \\
(n=37)\end{array}$ & $\begin{array}{l}\text { Tram } \\
(n=18)\end{array}$ & $\begin{array}{l}\text { Metro } \\
(\mathrm{n}=4)\end{array}$ \\
\hline \multicolumn{2}{|c|}{ Denmark } & 89.6 & 126.7 & 26.8 & 103.9 & 99.3 & 35.5 & 76.0 & 285.1 & 282.0 & 259.1 & 172.5 & 418.9 & 95.7 & 536.1 \\
\hline \multicolumn{2}{|c|}{ Netherlands } & 65.8 & 89.6 & 12.9 & 65.8 & 79.9 & 24.9 & 43.2 & 292.4 & 149.8 & 238.9 & 130.3 & 131.5 & 232.1 & 221.7 \\
\hline \multicolumn{2}{|c|}{ Slovenia } & 60.7 & 75.8 & 22.2 & 59.7 & 55.6 & 28.6 & 28.8 & 228.8 & 224.5 & 193.5 & 191.2 & NA & NA & NA \\
\hline \multicolumn{2}{|c|}{ Switzerland } & 39.3 & 49.7 & 12.0 & 42.3 & 32.4 & 18.9 & 17.9 & 123.4 & 195.9 & 194.5 & 64.4 & 348.9 & 185.8 & NA \\
\hline \multirow[t]{5}{*}{ Spain } & Gipuzkoa & 55.8 & 67.8 & 19.8 & 48.3 & 74.0 & 27.8 & 30.3 & 101.6 & 55.1 & 65.6 & 54.5 & NA & NA & NA \\
\hline & Granada & 177.8 & 202.3 & 92.5 & 225.8 & 82.4 & 125.5 & 268.4 & 135.2 & 144.4 & 383.5 & 93.6 & NA & NA & NA \\
\hline & Menorca & 93.5 & 108.9 & 19.0 & 86.9 & 86.2 & 25.3 & 57.3 & 166.5 & 255.5 & 291.5 & 256.7 & NA & NA & NA \\
\hline & Sabadell & 107.7 & 116.6 & 48.4 & 105.23 & 122.5 & 64.4 & 50.7 & 153.1 & 148.1 & 211.3 & 149.7 & 211.7 & NA & NA \\
\hline & Valencia & 80.5 & 103.6 & 27.1 & 71.7 & 88.4 & 32.8 & 36.1 & 93.8 & 158.9 & 162.1 & 156.9 & 967.2 & NA & NA \\
\hline \multicolumn{2}{|l|}{ Overall } & 75.5 & 94.2 & 23.0 & 72.0 & 78.9 & 33.0 & 35.1 & 157.0 & 171.3 & 208.5 & 140.5 & 389.7 & 202.0 & 536.1 \\
\hline
\end{tabular}

NA: not applicable, children in these regions did not report any travel via train, tram, or metro.

Mathematical note: the sum of medians does not equal the total median. 
Table 4

Individual characteristics and geometric mean ratios of radiofrequency electromagnetic fields exposure by general frequency bands. ${ }^{\mathrm{a}}$

\begin{tabular}{|c|c|c|c|c|c|c|c|c|c|c|c|c|c|c|c|c|c|c|c|}
\hline \multicolumn{2}{|c|}{ Individual characteristics } & \multicolumn{3}{|l|}{ Total } & \multicolumn{3}{|l|}{ DECT } & \multicolumn{3}{|l|}{ Broadcast } & \multicolumn{3}{|l|}{ Uplink } & \multicolumn{3}{|l|}{ Downlink } & \multicolumn{3}{|l|}{ Wifi } \\
\hline & & \multirow{2}{*}{$\begin{array}{l}\text { GM ratio } \\
0.99\end{array}$} & \multicolumn{2}{|c|}{$95 \% \mathrm{CI}$} & \multirow{2}{*}{$\begin{array}{l}\text { GM ratio } \\
0.90\end{array}$} & \multicolumn{2}{|c|}{$95 \% \mathrm{CI}$} & \multirow{2}{*}{$\begin{array}{l}\text { GM ratio } \\
0.85\end{array}$} & \multicolumn{2}{|c|}{$95 \% \mathrm{CI}$} & \multirow{2}{*}{$\begin{array}{l}\text { GM ratio } \\
1.20\end{array}$} & \multicolumn{2}{|c|}{$95 \% \mathrm{CI}$} & \multirow{2}{*}{$\begin{array}{l}\text { GM ratio } \\
0.97\end{array}$} & \multicolumn{2}{|c|}{$95 \% \mathrm{CI}$} & \multirow{2}{*}{$\begin{array}{l}\text { GM ratio } \\
1.03\end{array}$} & \multicolumn{2}{|c|}{$95 \% \mathrm{CI}$} \\
\hline Age & (Year) & & 0.96 & 1.03 & & 0.85 & 0.95 & & 0.81 & 0.89 & & 1.15 & 1.26 & & 0.93 & 1.01 & & 1.00 & 1.07 \\
\hline Sex & Male & 1.00 & & & 1.00 & & & 1.00 & & & 1.00 & & & 1.00 & & & 1.00 & & \\
\hline & Female & 1.02 & 0.84 & 1.24 & 1.12 & 0.83 & 1.52 & 0.96 & 0.72 & 1.29 & 1.85 & 1.40 & 2.46 & 1.01 & 0.80 & 1.27 & 0.96 & 0.78 & 1.19 \\
\hline Urbanicity of & Rural & 1.00 & & & 1.00 & & & 1.00 & & & 1.00 & & & 1.00 & & & 1.00 & & \\
\hline home & Suburban & 1.26 & 0.96 & 1.67 & 3.47 & 2.21 & 5.43 & 1.17 & 0.74 & 1.84 & 1.15 & 0.75 & 1.76 & 1.26 & 0.91 & 1.75 & 1.27 & 0.94 & 1.72 \\
\hline & Urban & 1.98 & 1.57 & 2.48 & 6.26 & 4.34 & 9.04 & 1.28 & 0.88 & 1.85 & 0.79 & 0.56 & 1.12 & 2.98 & 2.28 & 3.90 & 1.11 & 0.87 & 1.42 \\
\hline Parent & Primary & 1.00 & & & 1.00 & & & 1.00 & & & 1.00 & & & 1.00 & & & 1.00 & & \\
\hline education & Secondary & 0.56 & 0.40 & 0.78 & 1.17 & 0.66 & 2.06 & 0.78 & 0.46 & 1.33 & 0.48 & 0.29 & 0.78 & 0.76 & 0.50 & 1.15 & 0.90 & 0.63 & 1.28 \\
\hline & University or + & 0.62 & 0.46 & 0.85 & 1.25 & 0.73 & 2.12 & 0.92 & 0.56 & 1.51 & 0.37 & 0.23 & 0.58 & 0.96 & 0.66 & 1.41 & 0.88 & 0.63 & 1.21 \\
\hline Number of & $\leq 4$ & 1.00 & & & 1.00 & & & 1.00 & & & 1.00 & & & 1.00 & & & 1.00 & & \\
\hline $\begin{array}{l}\text { people } \\
\text { living in } \\
\text { home }\end{array}$ & 5 or + & 0.87 & 0.68 & 1.10 & 0.81 & 0.54 & 1.21 & 0.94 & 0.64 & 1.37 & 0.87 & 0.60 & 1.24 & 0.89 & 0.67 & 1.19 & 0.92 & 0.72 & 1.19 \\
\hline
\end{tabular}

Abbreviations: CI, Confidence Intervals; DECT, digital enhanced cordless telecommunications; GM, geometric mean; WiFi, Wireless Fidelity.

${ }^{a}$ Mixed effects models with region random effects, except for the model for age, due to the high correlation between region and age.

Table 5

Device use habits and geometric mean ratios of electromagnetic fields exposure by general frequency bands. ${ }^{\text {a }}$

\begin{tabular}{|c|c|c|c|c|c|c|c|c|c|c|c|c|c|c|c|c|c|c|c|}
\hline \multirow[t]{2}{*}{ Device use habits } & & \multicolumn{3}{|l|}{ Total } & \multicolumn{3}{|l|}{ DECT } & \multicolumn{3}{|l|}{ Broadcast } & \multicolumn{3}{|l|}{ Uplink } & \multicolumn{3}{|l|}{ Downlink } & \multicolumn{3}{|l|}{ WiFi } \\
\hline & & \multirow{2}{*}{$\begin{array}{l}\text { GM ratio } \\
1.00\end{array}$} & \multicolumn{2}{|c|}{$95 \% \mathrm{CI}$} & \multirow{2}{*}{$\begin{array}{l}\text { GM ratio } \\
1.00\end{array}$} & \multicolumn{2}{|c|}{$95 \% \mathrm{CI}$} & \multirow{2}{*}{$\begin{array}{l}\text { GM ratio } \\
1.00\end{array}$} & \multicolumn{2}{|c|}{$95 \% \mathrm{CI}$} & \multirow{2}{*}{$\frac{\text { GM ratio }}{1.00}$} & \multicolumn{2}{|c|}{$95 \% \mathrm{CI}$} & \multirow{2}{*}{$\begin{array}{l}\text { GM ratio } \\
1.00\end{array}$} & \multicolumn{2}{|c|}{$95 \% \mathrm{CI}$} & \multirow{2}{*}{$\begin{array}{l}\text { GM ratio } \\
1.00\end{array}$} & \multicolumn{2}{|c|}{$95 \% \mathrm{CI}$} \\
\hline DECT phone in & No & & & & & & & & & & & & & & & & & & \\
\hline home & Yes & 1.10 & 0.87 & 1.38 & 1.88 & 1.32 & 2.68 & 1.49 & 1.05 & 2.12 & 0.79 & 0.57 & 1.11 & 0.95 & 0.72 & 1.25 & 0.99 & 0.77 & 1.27 \\
\hline \multirow[t]{2}{*}{ WiFi in home } & No & 1.00 & & & 1.00 & & & 1.00 & & & 1.00 & & & 1.00 & & & 1.00 & & \\
\hline & Yes & 0.87 & 0.55 & 1.40 & 1.23 & 0.60 & 2.51 & 1.32 & 0.65 & 2.68 & 0.63 & 0.32 & 1.23 & 0.69 & 0.40 & 1.20 & 1.09 & 0.67 & 1.79 \\
\hline \multirow{2}{*}{$\begin{array}{l}\text { Use of mobile } \\
\text { phone at least } \\
1 \times / \text { week }\end{array}$} & No & 1.00 & & & 1.00 & & & 1.00 & & & 1.00 & & & 1.00 & & & 1.00 & & \\
\hline & Yes & 1.09 & 0.83 & 1.43 & 1.23 & 0.81 & 1.88 & 0.94 & 0.62 & 1.44 & 2.02 & 1.37 & 2.99 & 1.35 & 0.98 & 1.85 & 1.02 & 0.76 & 1.36 \\
\hline \multirow[t]{2}{*}{ Use of smartphone } & No & 1.00 & & & 1.00 & & & 1.00 & & & 1.00 & & & 1.00 & & & 1.00 & & \\
\hline & Yes & 1.15 & 0.88 & 1.49 & 1.45 & 0.96 & 2.18 & 0.86 & 0.57 & 1.29 & 2.11 & 1.45 & 3.08 & 1.46 & 1.07 & 1.98 & 1.16 & 0.88 & 1.54 \\
\hline \multirow{3}{*}{$\begin{array}{l}\text { Mobile phone call } \\
\text { frequency }\end{array}$} & None & 1.00 & & & 1.00 & & & 1.00 & & & 1.00 & & & 1.00 & & & 1.00 & & \\
\hline & 1 call/day & 1.11 & 0.86 & 1.42 & 1.14 & 0.77 & 1.67 & 1.13 & 0.77 & 1.66 & 1.58 & 1.11 & 2.27 & 0.96 & 0.72 & 1.28 & 1.02 & 0.78 & 1.33 \\
\hline & $\begin{array}{l}\geq 2 \text { calls/ } \\
\text { day }\end{array}$ & 1.16 & 0.86 & 1.58 & 1.48 & 0.92 & 2.37 & 0.86 & 0.54 & 1.38 & 1.95 & 1.25 & 3.02 & 1.34 & 0.94 & 1.92 & 0.96 & 0.69 & 1.33 \\
\hline \multirow{3}{*}{$\begin{array}{l}\text { Mobile phone call } \\
\text { duration }\end{array}$} & None & 1.00 & & & 1.00 & & & 1.00 & & & 1.00 & & & 1.00 & & & 1.00 & & \\
\hline & $\begin{array}{l}1-5 \mathrm{~min} / \\
\text { day }\end{array}$ & 1.10 & 0.87 & 1.38 & 1.30 & 0.91 & 1.87 & 0.93 & 0.65 & 1.33 & 1.68 & 1.20 & 2.35 & 1.01 & 0.77 & 1.33 & 0.98 & 0.76 & 1.26 \\
\hline & $\begin{array}{l}>5 \mathrm{~min} / \\
\text { day }\end{array}$ & 1.37 & 0.94 & 2.00 & 0.95 & 0.53 & 1.71 & 1.16 & 0.65 & 2.08 & 2.29 & 1.33 & 3.96 & 1.12 & 0.72 & 1.75 & 1.06 & 0.71 & 1.60 \\
\hline \multirow{3}{*}{$\begin{array}{l}\text { Internet use on } \\
\text { mobile phone }\end{array}$} & None & 1.00 & & & 1.00 & & & 1.00 & & & 1.00 & & & 1.00 & & & 1.00 & & \\
\hline & $\begin{array}{l}1-30 \mathrm{~min} / \\
\text { day }\end{array}$ & 1.31 & 0.97 & 1.77 & 1.33 & 0.83 & 2.13 & 1.10 & 0.69 & 1.76 & 1.57 & 1.02 & 2.41 & 1.55 & 1.10 & 2.21 & 1.33 & 0.97 & 1.82 \\
\hline & $\begin{array}{l}>30 \mathrm{~min} / \\
\text { day }\end{array}$ & 1.26 & 0.92 & 1.72 & 1.38 & 0.84 & 2.29 & 1.08 & 0.65 & 1.78 & 2.24 & 1.42 & 3.51 & 1.30 & 0.90 & 1.88 & 1.71 & 1.22 & 2.38 \\
\hline SMS frequency & None & 1.00 & & & 1.00 & & & 1.00 & & & 1.00 & & & 1.00 & & & 1.00 & & \\
\hline & 1-5/day & 1.20 & 0.88 & 1.65 & 1.77 & 1.09 & 2.88 & 1.34 & 0.82 & 2.18 & 1.65 & 1.04 & 2.60 & 1.26 & 0.87 & 1.81 & 0.94 & 0.67 & 1.31 \\
\hline & $>$ 5/day & 1.35 & 0.94 & 1.95 & 1.46 & 0.83 & 2.58 & 1.11 & 0.63 & 1.95 & 1.67 & 0.98 & 2.85 & 1.41 & 0.92 & 2.16 & 1.01 & 0.68 & 1.50 \\
\hline App-based & None & 1.00 & & & 1.00 & & & 1.00 & & & 1.00 & & & 1.00 & & & 1.00 & & \\
\hline messaging & 1-10/day & 1.26 & 0.93 & 1.73 & 1.19 & 0.73 & 1.95 & 0.90 & 0.55 & 1.47 & 1.37 & 0.88 & 2.15 & 1.45 & 1.00 & 2.08 & 1.37 & 0.98 & 1.90 \\
\hline & $>10 /$ day & 1.11 & 0.82 & 1.50 & 0.91 & 0.56 & 1.48 & 0.72 & 0.44 & 1.17 & 2.01 & 1.30 & 3.10 & 1.15 & 0.81 & 1.64 & 1.56 & 1.13 & 2.16 \\
\hline $\begin{array}{l}\text { Mobile phone at } \\
\text { night }\end{array}$ & $\begin{array}{l}\text { Off, flight } \\
\text { mode, } \\
\text { outside } \\
\text { bedroom }\end{array}$ & 1.00 & & & 1.00 & & & 1.00 & & & 1.00 & & & 1.00 & & & 1.00 & & \\
\hline & $\begin{array}{l}\text { Turned on } \\
\text { inside } \\
\text { bedroom }\end{array}$ & 1.22 & 0.95 & 1.56 & 1.24 & 0.84 & 1.82 & 1.01 & 0.68 & 1.48 & 1.81 & 1.27 & 2.58 & 1.26 & 0.94 & 1.69 & 1.59 & 1.22 & 2.07 \\
\hline Use of tablet & No & 1.00 & & & 1.00 & & & 1.00 & & & 1.00 & & & 1.00 & & & 1.00 & & \\
\hline & Yes & 0.91 & 0.74 & 1.11 & 1.06 & 0.77 & 1.44 & 1.04 & 0.76 & 1.42 & 1.01 & 0.75 & 1.36 & 0.78 & 0.61 & 0.99 & 1.19 & 0.96 & 1.47 \\
\hline
\end{tabular}

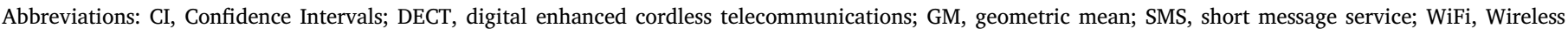
Fidelity.

${ }^{a}$ Mixed effects models with region random effects adjusted by sex, urbanicity of home, and parent education. 
Table 6

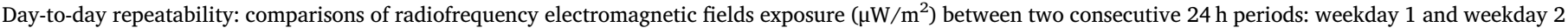
$(n=497)$, or weekend day 1 and weekend day $2(n=167)$.

\begin{tabular}{|c|c|c|c|c|c|c|c|}
\hline & \multicolumn{3}{|c|}{ Day 1} & \multicolumn{3}{|c|}{ Day 2} & \multirow[t]{2}{*}{ Intraclass correlation $(95 \% \mathrm{CI})^{\mathrm{a}}$} \\
\hline & Min & Median & Max & Min & Median & Max & \\
\hline \multicolumn{8}{|c|}{ Weekday } \\
\hline \multicolumn{8}{|c|}{ General frequency bands } \\
\hline Total & 2.2 & 148.7 & 8002.0 & 0.5 & 57.8 & 6895.9 & $0.57(0.52,0.61)$ \\
\hline DECT & 0.0 & 0.2 & 142.1 & 0.0 & 0.2 & 1055.8 & $0.72(0.68,0.75)$ \\
\hline Broadcast & 0.0 & 7.9 & 7765.3 & 0.0 & 7.1 & 6890.2 & $0.74(0.71,0.77)$ \\
\hline Uplink & 0.0 & 2.3 & 767.3 & 0.0 & 2.0 & 1715.8 & $0.26(0.21,0.32)$ \\
\hline Downlink & 0.1 & 20.8 & 3440.7 & 0.1 & 18.0 & 3688.3 & $0.45(0.40,0.50)$ \\
\hline WiFi & 0.0 & 12.9 & 312.6 & 0.0 & 12.2 & 97.1 & $0.36(0.30,0.42)$ \\
\hline \multicolumn{8}{|l|}{ Diurnal } \\
\hline Day & 2.5 & 71.4 & $11,938.7$ & 0.4 & 66.4 & 9358.7 & $0.42(0.37,0.47)$ \\
\hline Night & 0.7 & 18.1 & 5095.2 & 0.5 & 20.3 & 4641.4 & $0.85(0.83,0.87)$ \\
\hline \multicolumn{8}{|l|}{ Weekend day } \\
\hline \multicolumn{8}{|c|}{ General frequency bands } \\
\hline Total & 1.0 & 73.3 & 4747.2 & 0.8 & 71.3 & $11,055.0$ & $0.43(0.31,0.57)$ \\
\hline DECT & 0.0 & 0.2 & 52.7 & 0.0 & 0.1 & 724.3 & $0.71(0.62,0.78)$ \\
\hline Broadcast & 0.3 & 7.4 & 3005.6 & 0.3 & 7.6 & 8660.1 & $0.78(0.71,0.84)$ \\
\hline Uplink & 0.1 & 3.5 & 806.7 & 0.1 & 3.1 & 634.8 & $0.21(0.09,0.41)$ \\
\hline Downlink & 0.1 & 16.3 & 1741.0 & 0.2 & 21.9 & $10,734.6$ & $0.53(0.41,0.65)$ \\
\hline WiFi & 0.0 & 1.3 & 129.7 & 0.0 & 1.2 & 112.9 & $0.38(0.25,0.53)$ \\
\hline \multicolumn{8}{|l|}{ Diurnal } \\
\hline Day & 0.9 & 87.0 & 5171.0 & 0.8 & 81.0 & 1655.9 & $0.32(0.20,0.48)$ \\
\hline Night & 0.7 & 21.2 & 3899.5 & 0.6 & 22.5 & 2651.5 & $0.78(0.72,0.84)$ \\
\hline
\end{tabular}

Abbreviations: CI, confidence interval; DECT, digital enhanced cordless telecommunications; Min, minimum; Max, maximum; WiFi, Wireless Fidelity.

a Exposures were log-transformed for intraclass correlation analysis.

Table 7

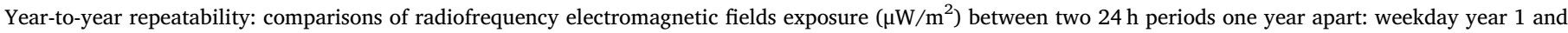
weekday year $2(n=28)$, or weekend day year 1 and weekend day year $2(n=9)$.

\begin{tabular}{|c|c|c|c|c|c|c|c|}
\hline & \multicolumn{3}{|c|}{ Year 1} & \multicolumn{3}{|c|}{ Year 2} & \multirow[t]{2}{*}{ Intraclass correlation $(95 \% \mathrm{CI})^{\mathrm{a}}$} \\
\hline & Min & Median & Max & Min & Median & Max & \\
\hline \multicolumn{8}{|l|}{ Weekday } \\
\hline \multicolumn{8}{|c|}{ General frequency bands } \\
\hline Total & 8.8 & 77.2 & 4115.1 & 5.9 & 123.5 & 972.0 & $0.49(0.32,0.66)$ \\
\hline DECT & 0.1 & 1.0 & 34.2 & 0.0 & 0.7 & 21.6 & $0.26(0.13,0.46)$ \\
\hline Broadcast & 1.1 & 16.3 & 366.6 & 8.8 & 19.9 & 356.3 & $0.71(0.57,0.82)$ \\
\hline Uplink & 0.1 & 0.8 & 401.9 & 0.1 & 0.5 & 72.0 & $0.11(0.03,0.33)$ \\
\hline Downlink & 2.1 & 44.5 & 645.9 & 2.2 & 89.3 & 767.6 & $0.55(0.39,0.70)$ \\
\hline WiFi & 0.1 & 0.9 & 19.5 & 0.2 & 0.7 & 49.2 & $0.12(0.04,0.31)$ \\
\hline \multicolumn{8}{|l|}{ Diurnal } \\
\hline Day & 12.1 & 93.3 & 6169.8 & 5.5 & 160.9 & 1179.2 & $0.39(0.24,0.57)$ \\
\hline Night & 2.2 & 62.8 & 1279.9 & 4.0 & 67.4 & 574.4 & $0.76(0.64,0.85)$ \\
\hline \multicolumn{8}{|l|}{ Weekend day } \\
\hline \multicolumn{8}{|c|}{ General frequency bands } \\
\hline Total & 15.1 & 79.7 & 603.9 & 14.9 & 152.5 & 4103.1 & $0.79(0.43,0.95)$ \\
\hline DECT & 0.1 & 1.2 & 7.7 & 0.0 & 0.5 & 18.5 & $\mathrm{~b}$ \\
\hline Broadcast & 0.7 & 11.5 & 461.8 & 2.1 & 29.7 & 269.3 & $0.80(0.46,0.95)$ \\
\hline Uplink & 0.1 & 2.4 & 38.4 & 0.3 & 2.1 & 116.8 & $0.17(0.00,0.93)$ \\
\hline Downlink & 5.6 & 30.8 & 240.3 & 1.0 & 108.4 & 3812.6 & $0.78(0.40,0.95)$ \\
\hline WiFi & 0.2 & 0.9 & 12.1 & 0.5 & 1.8 & 8.4 & $0.31(0.03,0.89)$ \\
\hline \multicolumn{8}{|l|}{ Diurnal } \\
\hline Day & 18.8 & 91.2 & 1008.9 & 15.0 & 213.8 & 5875.2 & $0.73(0.38,0.92)$ \\
\hline Night & 2.2 & 45.2 & 266.4 & 4.4 & 52.2 & 558.7 & $0.75(0.37,0.94)$ \\
\hline
\end{tabular}

Abbreviations: CI, confidence interval; DECT, digital enhanced cordless telecommunications; Min, minimum; Max, maximum; WiFi, Wireless Fidelity.

a Exposures were log-transformed for intraclass correlation analysis.

b Too few observations to complete analysis.

on at night inside the bedroom were associated with higher WiFi exposure.

For day-to-day repeatability among weekdays, we observed an ICC of 0.57 for total exposure (Table 6, Supplementary Fig. S2A). DECT and broadcast exposures showed a higher ICC ( 0.72 and 0.74 , respectively). Uplink exposure had the most day-to-day variability (ICC 0.26 ). We also observed a higher ICC for total exposure at night $(0.85)$ than during the day (0.42). Similar results were found for day-to-day variability among weekend days (Table 6, Supplementary Fig. S2B).

Of the 30 children from Sabadell in the repeat subsample, 28 had valid repeated measurements one year later. Regarding year-to-year repeatability among weekdays, we observed an ICC of 0.49 for total exposure (Table 7, Supplementary Fig. S2C). Broadcast exposure was 
the most stable over one year (ICC 0.71), while uplink and WiFi had the most variation (ICC 0.11 and 0.12 , respectively). We also observed a higher ICC of total exposure at night (0.76) than during the day (0.39). Similar results were found for year-to-year repeatability among weekend days (Table 7, Supplementary Fig. S2D). Among the participants of this repeatability sub-study, handheld device use slightly increased over a year, mainly through internet use on mobile phone (Supplementary Table S6).

In sensitivity analyses, we found no important differences in exposure between children that carried the exposimeter in a handbag or backpack or those that carried it on the body (data not shown). Medians of TWA total exposure with two frequencies that were excluded from the main analysis due to crosstalk concerns (Mobile $3.5 \mathrm{GHz}$ and ISM $5.8 \mathrm{GHz}$ ) did not differ significantly from the main analysis (data not shown).

\section{Discussion}

In this study, we closely examined the levels, sources, and individual determinants of personal environmental RF-EMF exposure over a period of up to three days in $>500$ children between 8 and 18 years old in five European countries. We also evaluated the day-today repeatability of this exposure in the whole sample and year-to-year repeatability in a smaller subsample. Main contributors to personal RFEMF exposure were downlink followed by broadcast. Uplink contributed less to exposure, except in Switzerland where broadcast, uplink, and downlink contributed almost equally. DECT and WiFi contributed very little to exposure. Individual characteristics, such as age and sex of child, urbanicity of home, and highest level of parent education, were associated with exposure in general frequency bands. Handheld device use habits were associated with uplink exposures. Most personal environmental RF-EMF day-to-day exposures were consistent within weekdays as well as within weekend days. Total exposure, downlink, and broadcast for the year-to-year exposures were also consistent. Personal environmental RF-EMF exposures to uplink, DECT, and WiFi were less consistent one year later which might be due to changes in device use habits. Personal environmental RF-EMF exposures in our study were much lower than International Commission on Non-Ionizing Radiation Protection (ICINIRP) reference levels (between 4.5 to $10 \mathrm{~W} / \mathrm{m}^{2}$ depending on the frequency band) (Guidelines for limiting exposure to time-varying electric, magnetic, and electromagnetic fields (up to $300 \mathrm{GHz}$ ), 1998).

Our study has some important strengths, including its sample size and wide age range across five countries, and the harmonized and detailed information regarding individual characteristics as well as handheld device use habits. To date, this is the first study to collect RFEMF exposure data from children of different ages simultaneously in different countries. Furthermore, with the use of mobile communication devices on the rise in the general population and with the age of first use lowering each year, it is critical to closely evaluate RF-EMF exposure in children. Also, RF-EMF exposimeters are one of the best current tools for environmental personal RF-EMF exposure (Roser et al., 2017). Additionally, participants wore the measurement devices for up to three days, allowing for a description of environmental RF-EMF exposure in different microenvironments and all hours of the day. Furthermore, collected information on individual characteristics was prone to little reporting error, considering their permanence (age, sex, parent education, urbanicity, etc.). Handheld device use habits and indoor RFEMF sources were reported at the end of the three-day data collection period, therefore there was little risk for recall bias. Finally, our study was the first of its kind to examine consistency of this type of measurements in a small subsample one year later.

Our study also has several limitations. While exposimeters are one of the best current tools for capturing environmental personal RF-EMF exposure, the device cannot control for several measurement uncertainties. For quantification of measurement uncertainties, please see supplemental materials (Supplemental Table S7). Other uncertainties include body shielding (interference of measurements by the body) or crosstalk between neighboring frequency bands, where power emitted in one frequency band is measured and reported in another band (Roser et al., 2017; Bolte et al., 2011). Body shielding was mostly relevant when participants moved around but less so when they placed the device on a flat surface close to them. Thus, we may have underestimated the difference between exposure at home and public transport (Bolte et al., 2011). We were able to correct measurements for some crosstalk errors using a DECT correction algorithm (Eeftens, 2017), but we could not control for crosstalk from other two frequency bands (Mobile $3.5 \mathrm{GHz}$ and ISM $5.8 \mathrm{GHz} / \mathrm{U} / \mathrm{NII} 1 / 2 \mathrm{e}$ ) and had to exclude them from analysis. Excluding these frequency bands means that we might have marginally underestimated total exposure in all regions, but in a sensitivity analysis, we showed that including these bands did not change our main results. Furthermore, much of our population was recruited from population-based birth cohort studies, which sometimes do not accurately represent the general population (Szklo, 1998). This would limit the external validity of our results. Our study details various exposure levels occurring in Europe in various populations. While we observed RF-EMF differences between regions in our sample, these might not be fully generalizable, as the possibility remains that their exposure does not represent the exposure in the general population. Also, some studies argue that exposimeters are not useful for accurately estimating RF-EMF exposure from own mobile phone use (Röösli et al., 2010; Bolte, 2016). While our measurements indicate downlink from fixed site transmitters to be the largest contributor to environmental exposure, it is likely that highest doses were received from uplink via sources close to body (handheld devices), such as a child holding a mobile phone next to the head during a call (Roser et al., 2017). Thus, our uplink measurements are roughly representing far-field exposure from mobile phones in the child's environment, and not representative of dose received to the head. Finally, while we collected detailed information on mobile device use habits, we did not collect information on how these habits varied during different hours of the day.

For total RF-EMF exposure, we observed higher exposure than in previous studies carried out in children in Germany, Slovenia, and Switzerland (Valič et al., 2015; Roser et al., 2017; Thomas et al., 2008b). However, we need to take into consideration that none of the previous studies used the same exposimeter that we used, not all previous studies measured the same frequency bands that we measured, and handheld device use habits as well as telecommunication infrastructure have since evolved. Therefore, it is difficult to compare results with previous studies. We found lower exposure to uplink than in the recent analysis of children in Switzerland (the German and Slovenian analyses did not measure uplink), but higher levels of downlink than all previous personal exposure studies in children. In the previous Swiss study (Roser et al., 2017), it was observed that uplink contributed most to exposure, which does not align with our findings in Switzerland or elsewhere. Our sample in Switzerland is generally comparable in age and mobile phone use habits to the previous Swiss study's sample (95\% of our Swiss sample reporting mobile phone use, while $100 \%$ of previous Swiss sample reported having a mobile phone), however the previous Swiss sample consisted of children living in exclusively rural areas, while only one-third of our Swiss sample lived in rural areas. Therefore, the higher downlink exposure could be due to a more urban sample, as higher people density has been correlated with more downlink exposure in our results and elsewhere (Bolte and Eikelboom, 2012). In fact, in our Swiss sample, median downlink levels in rural areas were $6.0 \mu \mathrm{W} / \mathrm{m}^{2}$, versus $23.7 \mu \mathrm{W} / \mathrm{m}^{2}$ in urban areas (data not shown). Furthermore, it is possible that changing handheld device use habits or telecommunication systems over time contributed to the discrepancies in results. However the previous Swiss study did not report frequency of mobile phone calls or app-based messaging (Roser et al., 2017).

In most regions, we found that broadcast was the second largest contributor to exposure, and this general frequency band was largely composed of FM Radio frequency band. In previous studies of exposure 
in children, FM Radio frequency band was not measured. As other studies have found (Valič et al., 2015; Roser et al., 2017; Thomas et al., 2008b), contributions from DECT and WiFi were very low. However, means of DECT and WiFi were slightly higher than means found in the previous Swiss study (Roser et al., 2017). This could be due to several factors such as a more urban sample or different measurement devices.

We found that age and sex of child, urbanicity of home, and parent education were significant determinants of increased environmental total RF-EMF exposure levels. While it is likely that older children and girls were using mobile phones more, it is also possible they were physically surrounded by a higher concentration of mobile phone users (compared to children that did not use or less frequently used mobile phones). Both situations might explain the increased environmental uplink exposure (uplink geometric mean increase of 85\%) in females vs. males and in older children (with the uplink geometric mean ratio increasing $20 \%$ with each year of age). Children living in urban environments experienced almost double the total exposure levels and three times the downlink exposure levels compared to children living in rural environments. This could be due to signal compensation for the built environment and high people density, given that more base stations are needed to support more users in a highly populated area. Children of parents with higher education were less exposed. All handheld device use habits regarding mobile phone use were associated with increased exposure to uplink, as expected; though they were not associated with total exposure. While the previous Swiss analysis illustrated mobile phone use habits, limited to having the phone turned on at night or using internet on the phone, were associated with higher total RF-EMF exposure, the authors did not assess the strength of this relationship (Roser et al., 2017). Smartphone use and intermediate categories of internet use on mobile phone and app-based messaging were associated with higher downlink exposure, perhaps indicative of mobile communication traffic in the child's environment. Having the phone turned on in the bedroom at night was also associated with higher WiFi exposure, which makes sense, considering the WiFi router would continue communicating with the mobile phone throughout the night, regardless of use.

Between weekday to weekday and weekend day to weekend day, we found that most measurements were consistent, except for uplink and WiFi. Uplink and WiFi measurements were not expected to be consistent, as RF-EMF emissions from these bands can vary depending on use of devices. Though collected within a small sample, our study was the first of its kind to assess repeatability of RF-EMF measurements one year later. These measurements in Spain demonstrated that year over year, downlink followed by broadcast were still the largest contributors to total RF-EMF, with DECT and WiFi contributing very little. Since broadcast and downlink measurements were consistent the following year, total measurements were also consistent. Uplink, DECT, and WiFi measurements were not similar one year later, which again was likely due to variations in device use habits. With today's constant changes in mobile communication devices and device use habits, it was surprising that total exposure did not vary significantly over one year. However, we suspect that comparing measurements perhaps several years apart would illustrate more significant changes in environmental RF-EMF exposures.

\section{Conclusion}

In this population sample, the most common sources of personal environmental RF-EMF exposure were downlink and broadcast and these exposures were consistent between days and one year later. Urbanicity was associated with higher total exposure. More frequent mobile phone use of any kind and longer mobile phone calls were associated with higher uplink exposure. It is important to continue evaluating RF-EMF exposure in children as device use habits, mobile devices, and mobile communication infrastructure continue to evolve.

\section{Conflict of interest}

None declared

\section{Sources of financial support}

GERoNiMO project: The research leading to these results has received funding from the European Community's Seventh Framework Programme (FP7/2007-2013) under grant agreement no. 603794 - the GERONIMO Project.

REMBRANDT project: This work is supported by Instituto de Salud Carlos III through the project CP13/00054 (Co-funded by European Regional Development Fund/European Social Fund) "Investing in your future").

HERMES project: This work is supported by the Swiss National Science Foundation (project number 138190). This research is also supported by the Swiss Research Foundation for Electricity and Mobile Communication (reference number 41).

ABCD, The Netherlands: This work is supported by the Netherlands Organization for Health Research and Development (grant 2100.0076) and within the programme Electromagnetic Fields and Health Research (grants 85600004 and 85800001).

DNBC, Denmark: This cohort was established by support from the Danish Epidemiology Science Centre; The Lundbeck Foundation (195/ 04, R100-A9193); Egmont Foundation; March of Dimes Birth Defect Foundation; University of Copenhagen Strategic Grant (IFSV 2012); and the Medical Research Council (SSVF 0646, 271-08-0839/06-066023, O602-01042B, 0602-02738B).

INMA, Menorca: This study was funded by grants from Instituto de Salud Carlos III (Red INMA G03/176; CB06/02/0041; 97/0588; 00/ 0021-2; PI061756; PS0901958; PI14/00677 incl. FEDER funds), CIBERESP, Beca de la IV convocatoria de Ayudas a la Investigación en Enfermedades Neurodegenerativas de La Caixa, and EC Contract No. QLK4-CT-2000-00263.

INMA, Granada: This research was supported in part by research grants from the Biomedical Research Networking Center-CIBER de Epidemiología y Salud Pública (CIBERESP), from the Institute of Health Carlos III -supported by European Regional Development Fund/FEDER (FIS-PI13/02406, FIS-PI14/00067, FIS-PI16/01820, FIS-PI16/01812 and FIS-PI16/01858), and from Junta de Andalucía-Consejería de Salud (SAS-PI-0675-2010 and PS-0506-2016).

INMA, Valencia: This study was funded by Grants from UE (FP7ENV-2011 cod 282957 and HEALTH.2010.2.4.5-1), Spain: ISCIII (G03/ 176; FIS-FEDER: PI11/01007, PI11/02591, PI11/02038, PI13/1944, PI13/2032, PI14/00891, PI14/01687, and PI16/1288; Miguel ServetFEDER CP11/00178, CP15/00025, and CPII16/00051), and Generalitat Valenciana: FISABIO (UGP 15-230, UGP-15-244, and UGP-15-249).

INMA, Sabadell: This study was funded by grants from Instituto de Salud Carlos III (Red INMA G03/176; CB06/02/0041; PI041436; PI081151 incl. FEDER funds; PI12/01890 incl. FEDER funds; CP13/ 00054 incl. FEDER funds, MS13/00054), CIBERESP, Generalitat de Catalunya-CIRIT 1999SGR 00241, Generalitat de Catalunya-AGAUR (2009 SGR 501, 2014 SGR 822), Fundació La marató de TV3 (090430), Spanish Ministry of Economy and Competitiveness (SAF2012-32991 incl. FEDER funds), Agence Nationale de Securite Sanitaire de l'Alimentation de l'Environnement et du Travail (1262C0010), EU Commission (261357, 308333 and 603794). ISGlobal is a member of the CERCA Program, Generalitat de Catalunya.

INMA, Gipuzkoa: This study was funded by grants from Instituto de Salud Carlos III (FIS-PI13/02187), CIBERESP, Department of Health of the Basque Government (2015111065), and the Provincial Government of Gipuzkoa (DFG15/221) and annual agreements with the municipalities of the study area.

ZuMe, Switzerland: This work is supported by the AWEL (Office for Waste, Water, Energy and Air) in Zurich. 


\section{Acknowledgements}

The authors would particularly like to thank Marco Zahner and all participants for their generous collaboration.

\section{Appendix A. Supplementary data}

Supplementary data to this article can be found online at https:// doi.org/10.1016/j.envint.2018.04.026.

\section{References}

Ahlbom, A., Bridges, J., de Seze, R., Hillert, L., Juutilainen, J., Mattsson, M.-O., et al., 2008. Possible effects of electromagnetic fields (EMF) on human health-opinion of the scientific committee on emerging and newly identified health risks (SCENIHR). Toxicology 246 (2-3), 248-250.

Baan, R., Grosse, Y., Lauby-Secretan, B., El Ghissassi, F., Bouvard, V., Benbrahim-Tallaa, L., et al., 2011. Carcinogenicity of radiofrequency electromagnetic fields. Lancet Oncol. 12 (7), 624-626.

Berg-Beckhoff, G., Blettner, M., Kowall, B., Breckenkamp, J., Schlehofer, B., Schmiedel, S., et al., 2009. Mobile phone base stations and adverse health effects: phase 2 of a cross-sectional study with measured radio frequency electromagnetic fields. Occup. Environ. Med. 66 (2), 124-130.

Bolte, J.F.B., 2016. Lessons learnt on biases and uncertainties in personal exposure measurement surveys of radiofrequency electromagnetic fields with exposimeters. Environ. Int. 94, 724-735.

Bolte, J.F.B., Eikelboom, T., 2012. Personal radiofrequency electromagnetic field measurements in the Netherlands: exposure level and variability for everyday activities, times of day and types of area. Environ. Int. 48, 133-142.

Bolte, J.F.B., van der Zande, G., Kamer, J., 2011. Calibration and uncertainties in personal exposure measurements of radiofrequency electromagnetic fields. Bioelectromagnetics 32 (8), 652-663.

Calvente, I., Fernández, M.F., Pérez-Lobato, R., Dávila-Arias, C., Ocón, O., Ramos, R., et al., 2015 Apr. Outdoor characterization of radio frequency electromagnetic fields in a Spanish birth cohort. Environ. Res. 138, 136-143.

Calvente, I., Pérez-Lobato, R., Núñez, M.-I., Ramos, R., Guxens, M., Villalba, J., et al., 2016 Jan. Does exposure to environmental radiofrequency electromagnetic fields cause cognitive and behavioral effects in 10-year-old boys? Bioelectromagnetics 37 (1), 25-36.

van Deventer, E., van Rongen, E., Saunders, R., 2011. WHO research agenda for radiofrequency fields. Bioelectromagnetics 32 (5), 417-421.

Eeftens, M., 2017. EMFtools/correct crosstalk.R [Internet]. Available from: https:// github.com/MarloesEeftens/EMFtools/blob/master/R/correct_crosstalk.R.

van Eijsden, M., Vrijkotte, T.G., Gemke, R.J., van der Wal, M.F., 2011. Cohort profile: the Amsterdam born children and their development (ABCD) study. Int. J. Epidemiol. 40 (5), 1176-1186.

Fields at Work - Products [Internet], 2016. Available from: http://www.fieldsatwork.ch/ index.php?page $=$ products

Frei, P., Mohler, E., Neubauer, G., Theis, G., Bürgi, A., Fröhlich, J., et al., 2009. Temporal and spatial variability of personal exposure to radio frequency electromagnetic fields. Environ. Res. 109 (6), 779-785.

Frei, P., Mohler, E., Bürgi, A., Fröhlich, J., Neubauer, G., Braun-Fahrländer, C., et al., 2010. Classification of personal exposure to radio frequency electromagnetic fields (RF-EMF) for epidemiological research: evaluation of different exposure assessment methods. Environ. Int. 36 (7), 714-720.

Gajšek, P., Ravazzani, P., Wiart, J., Grellier, J., Samaras, T., Thuróczy, G., 2015 Jan. Electromagnetic field exposure assessment in Europe radiofrequency fields (10 MHz-6 GHz). J Expo Sci Environ Epidemiol. 25 (1), 37-44.

Gallastegi, M., Guxens, M., Jiménez-Zabala, A., Calvente, I., Fernández, M., Birks, L., et al., 2016. Characterisation of exposure to non-ionising electromagnetic fields in the Spanish INMA birth cohort: study protocol. BMC Public Health 16, 167.

Guidelines for limiting exposure to time-varying electric, magnetic, and electromagnetic fields (up to $300 \mathrm{GHz}$ ), 1998. International commission on non-ionizing radiation protection. Health Phys. 74 (4), 494-522.

Guxens, M., 2016. Radiofrequency ElectroMagnetic Fields Exposure and BRAiN DevelopmenT From Exposure Assessment to Dose-response Assessment (REMBRANDT) - Project - ISGLOBAL [Internet]. Available from: https://www. isglobal.org/en/project/-/asset_publisher/qf6QOKuKkIC3/content/radiofrequencyelectromagnetic-fields-exposure-and-brain-development-from-exposure-assessmentto-dose-response-assessment-rembrandt.

Guxens, M., Ballester, F., Espada, M., Fernández, M.F., Grimalt, J.O., Ibarluzea, J., et al., 2012. Cohort profile: the INMA-INfancia y Medio Ambiente-(environment and childhood) project. Int. J. Epidemiol. 41 (4), 930-940.

Guxens, M., Vermeulen, R., van Eijsden, M., Beekhuizen, J., Vrijkotte, T.G.M., van Strien, R.T., et al., 2016. Outdoor and indoor sources of residential radiofrequency electromagnetic fields, personal cell phone and cordless phone use, and cognitive function in 5-6 years old children. Environ. Res. 150, 364-374.
Hauri, D.D., Spycher, B., Huss, A., Zimmermann, F., Grotzer, M., vonder Weid, N., et al., 2014. Exposure to radio-frequency electromagnetic fields from broadcast transmitters and risk of childhood cancer: a census-based cohort study. Am. J. Epidemiol. 179 (7), 843-851.

Heinrich, S., Thomas, S., Heumann, C., von Kries, R., Radon, K., 2011 Jan. The impact of exposure to radio frequency electromagnetic fields on chronic well-being in young people - a cross-sectional study based on personal dosimetry. Environ. Int. 37 (1), 26-30.

Huss, A., van Eijsden, M., Guxens, M., Beekhuizen, J., van Strien, R., Kromhout, H., et al., 2015. Environmental radiofrequency electromagnetic fields exposure at home, mobile and cordless phone use, and sleep problems in 7-year-old children. PLoS One 10 (10), e0139869.

Inyang, I., Benke, G., McKenzie, R., Abramson, M., 2008. Comparison of measuring instruments for radiofrequency radiation from mobile telephones in epidemiological studies: implications for exposure assessment. J Expo Sci Environ Epidemiol. 18 (2), 134-141.

Juhász, P., Bakos, J., Nagy, N., Jánossy, G., Finta, V., Thuróczy, G., 2011 Dec. RF personal exposimetry on employees of elementary schools, kindergartens and day nurseries as a proxy for child exposures. Prog. Biophys. Mol. Biol. 107 (3), 449-455.

Kheifets, L., Repacholi, M., Saunders, R., van Deventer, E., 2005. The sensitivity of children to electromagnetic fields. Pediatrics 116 (2) (e303-13).

Markov, M., Grigoriev, Y., 2015. Protect children from EMF. Electromagn Biol Med. 34 (3), 251-256.

Merzenich, H., Schmiedel, S., Bennack, S., Brüggemeyer, H., Philipp, J., Blettner, M., et al., 2008. Childhood leukemia in relation to radio frequency electromagnetic fields in the vicinity of TV and radio broadcast transmitters. Am. J. Epidemiol. 168 (10), 1169-1178.

Olsen, J., Melbye, M., Olsen, S.F., Sørensen, T.I., Aaby, P., Andersen, A.M., et al., 2001. The Danish National Birth Cohort-its background, structure and aim. Scand J Public Health. 29 (4), 300-307.

Otto, M., von Mühlendahl, K.E., 2007. Electromagnetic fields (EMF): do they play a role in children's environmental health (CEH)? Int. J. Hyg. Environ. Health 210 (5), 635-644.

R Core Team, 2013. R: The R Project for Statistical Computing [Internet]. R Foundation for Statistical Computing, Vienna, Austria (cited 2016 Dec 5. Available from:). https://www.r-project.org/.

Redmayne, M., 2016. International policy and advisory response regarding children's exposure to radio frequency electromagnetic fields (RF-EMF). Electromagn Biol Med. 35 (2), 176-185.

Rice, D., Barone, S., 2000. Critical periods of vulnerability for the developing nervous system: evidence from humans and animal models. Environ. Health Perspect. 108 (Suppl. 3), 511-533.

Röösli, M., 2016. Population based personal radiofrequency electromagnetic field exposure measurements in Zurich [Internet]. Available from: http://www.swisstph.ch/ en/resources/projects/project-details.html?tx_x4euniprojectsgeneral_ pi1\%5BshowUid $\% 5 \mathrm{D}=1269$.

Röösli, M., Hug, K., 2011. Wireless communication fields and non-specific symptoms of ill health: a literature review. Wien Med Wochenschr 1946161 (9-10), 240-250.

Röösli, M., Frei, P., Bolte, J., Neubauer, G., Cardis, E., Feychting, M., et al., 2010. Conduct of a personal radiofrequency electromagnetic field measurement study: proposed study protocol. Environ. Health 9, 23.

Röösli, M., Struchen, B., Eeftens, M., Roser, K., 2016. Personal measurements of high frequency electromagnetic fields in a test population in the canton of Zurich [Internet]. Swiss Tropical and Public Health Institute, Basel, Switzerland: Departement Epidemiologie und Public Health; Im Auftrag des AWEL. Amt für Abfall, Wasser, Energie und Luft in Zürich Available from: http://www.awel.zh.ch/dam/ baudirektion/awel/luft_asbest_elektrosmog/elektrosmog/dokumente/PersMeas_ AWEL 2016.pdf.

Rosenberg, S., 2013. Cell phones and children: follow the precautionary road. Pediatr. Nurs. 39 (2), 65-70.

Roser, K., Schoeni, A., Struchen, B., Zahner, M., Eeftens, M., Fröhlich, J., et al., 2017. Personal radiofrequency electromagnetic field exposure measurements in Swiss adolescents. Environ. Int. 99, 303-314.

Schoeni, A., Roser, K., Röösli, M., 2015a. Symptoms and cognitive functions in adolescents in relation to mobile phone use during night. PLoS One 10 (7), e0133528.

Schoeni, A., Roser, K., Röösli, M., 2015b. Memory performance, wireless communication and exposure to radiofrequency electromagnetic fields: a prospective cohort study in adolescents. Environ. Int. 85, 343-351.

Schoeni, A., Roser, K., Bürgi, A., Röösli, M., 2016. Symptoms in Swiss adolescents in relation to exposure from fixed site transmitters: a prospective cohort study. Environ. Health 15, 77.

Sienkiewicz, Z., Jones, N., Bottomley, A., 2005. Neurobehavioural effects of electromagnetic fields. Bioelectromagnetics 26 (S7) (S116-26).

Swedish Radiation Safety Authority, 2017. Magnetic Fields and Wireless Technology [Internet]. Sweden, Stockholm (cited 2017 Aug 9). Available from: http://www. stralsakerhetsmyndigheten.se/In-English/About-the-Swedish-Radiation-SafetyAuthority1/Magnetic-fields-and-wireless-technology/.

Szklo, M., 1998. Population-based cohort studies. Epidemiol. Rev. 20 (1), 81-90.

Thomas, S., Kühnlein, A., Heinrich, S., Praml, G., Nowak, D., von Kries, R., et al., 2008a. Personal exposure to mobile phone frequencies and well-being in adults: a crosssectional study based on dosimetry. Bioelectromagnetics 29 (6), 463-470. 
Thomas, S., Kühnlein, A., Heinrich, S., Praml, G., von Kries, R., Radon, K., 2008b. Exposure to mobile telecommunication networks assessed using personal dosimetry and well-being in children and adolescents: the German MobilEe-study. Environ. Health 7, 54.

Thomas, S., Heinrich, S., von Kries, R., Radon, K., 2009. Exposure to radio-frequency electromagnetic fields and behavioural problems in Bavarian children and adolescents. Eur. J. Epidemiol. 25 (2), 135-141.

Valič, B., Kos, B., Gajšek, P., 2015. Typical exposure of children to EMF: exposimetry and dosimetry. Radiat. Prot. Dosim. 163 (1), 70-80.

Vermeeren, G., Markakis, I., Goeminne, F., Samaras, T., Martens, L., Joseph, W., 2013
Nov. Spatial and temporal RF electromagnetic field exposure of children and adults in indoor micro environments in Belgium and Greece. Prog. Biophys. Mol. Biol. 113 (2), 254-263.

Vermeulen, R., 2016. GERoNiMO Workpackage 6: Improved Evaluation of Cumulative and Integrated RF and IF Exposure [Internet]. Generalized EMF Research Using Novel Methods. Available from: http://radiation.isglobal.org/index.php/en/geronimoworkpackages/workpackage-6.

Viel, J.-F., Cardis, E., Moissonnier, M., de Seze, R., Hours, M., 2009. Radiofrequency exposure in the French general population: band, time, location and activity variability. Environ. Int. 35 (8), 1150-1154. 